\title{
Erythroleukemia induction by Friend murine leukemia virus: insertional activation of a new member of the ets gene family, Fli-1, closely linked to c-ets-1
}

\author{
Yaacov Ben-David, Elizabeth B. Giddens, Kenneth Letwin, and Alan Bernstein ${ }^{1}$ \\ Division of Molecular and Developmental Biology, Samuel Lunenfeld Research Institute, Mount Sinai Hospital, Toronto, \\ Ontario M5G 1X5 Canada; 'Department of Molecular and Medical Genetics, University of Toronto, Toronto, Ontario, \\ Canada
}

The retroviral integration site $\mathrm{Fli}-\mathbf{1}$ is rearranged in $75 \%$ of the erythroleukemia cell clones induced by Friend murine leukemia virus (F-MuLV), whereas Spi-1/PU.1, a member of the ets family of DNA-binding proteins, is rearranged in $95 \%$ of the erythroleukemias induced by Friend spleen focus-forming virus (SFFV). To determine the transcriptional domain defined by Fli-1, we have isolated a cDNA clone that is highly expressed only in erythroleukemia cell lines with Fli-1 rearrangements. The protein sequence of this cDNA is very similar to Erg2, another member of the ets gene family. The hydrophilic carboxy-terminal end of the Fli-1 cDNA shares significant sequence similarity to the DNA-binding ETS domain found in all members of the ets family. PFGE analysis localized Fli-1 within $240 \mathrm{~kb}$ of the ets-1 proto-oncogene on mouse chromosome 9 and human chromosome $11 \mathrm{q} 23$, suggesting that $e t s-1$ and $F l i-1$ arose from a common ancestral gene by gene duplication. The involvement of the murine Fli-1, Spi-1, and avian v-ets genes in erythroleukemia induction suggests that activation of ets gene family members plays an important role in the progression of these multistage malignancies.

[Key Words: F-MuLV; erythroleukemia; Fli-1; ets-1]

Received February 6, 1991; revised version accepted March 15, 1991.

The hematopoietic system is composed of a hierarchy of cells, ranging from the pluripotent stem cell, committed myeloid and lymphoid progenitor cells, to terminally differentiated blood cells (Metcalf 1988; Sachs 1987). The molecular mechanisms that control the developmental and proliferative decisions of the pluripotent hematopoietic stem cell are largely unknown. The extreme cellular heterogeneity of hematopoietic populations, combined with the low frequency of stem cells, has hampered experimental approaches to this problem. The generation of mutations that affect stem cell function and the molecular analysis of existing developmental mutations that control hematopoiesis (Pawson and Bernstein 1990) provide two powerful genetic strategies for identifying and characterizing the genes that control normal blood cell formation. In addition, because cellular genes involved in leukemic transformation may also have a role in regulating normal stem cell function, the identification of such genes may provide insights into both normal and leukemic hematopoiesis.

\footnotetext{
${ }^{1}$ Corresponding author.
}

Transformation by certain retroviruses can involve the integration of proviral DNA near or within specific cellular genes. Such integration events most frequently lead to the elevated expression of these genes (for review, see in Peters 1990), although the tumor suppressor gene p53 can also be inactivated by retroviral integration of the Friend leukemia virus (Ben-David et al. 1988, 1990b). The analysis of common retroviral integration events can, therefore, be used to identify and clone novel transforming genes involved in tumorigenesis. Using this approach, a large number of genes important in the leukemic transformation of hematopoietic cells, including pim-1, c-myc, c-myb, Evi-1, Fim-3/c-fms, Spi-1, and Fli-1 have been isolated (Peters 1990).

The Fli-1 and Spi-1 genes have been shown by us and others (Moreau-Gachelin et al. 1988; Ben-David et al. 1990) to be involved in erythroleukemia induction by various strains of Friend leukemia virus. Fli-1 (Friend leukemia integration-site 1 ) is rearranged in $75 \%$ of independently isolated erythroleukemic clones from mice inoculated at birth with the replication-competent Friend murine leukemia virus (F-MuLV). In contrast, Spi- 
1 (SFFV-proviral integration-site 1 ) is rearranged in the majority of erythroleukemias induced by injection of the polycythemia (FV-P)- or anemia (FV-A)-inducing strains of Friend virus (Moureau-Gachelin et al. 1988,1990). The FV-P and FV-A strains of Friend virus are complexes of a replication-defective spleen focus-forming virus (SFFV-P and SFFV-A) and a replication-competent F-MuLV (for review, see Kabat 1990). Spi-1 is rearranged only in FV-Pand FV-A-induced erythroleukemias and not in the leukemias induced by F-MuLV (Moreau-Gachelin et al. 1988; Ben-David et al. 1990a). In contrast, the Fli-1 locus is only rearranged in the erythroleukemias induced by F-MuLV and not in the erythroleukemias induced by the FV-P or FV-A viral complexes (Ben-David et al. 1990a). These observations have raised the possibility that two distinct events are involved in the induction of erythroleukemias by F-MuLV or FV-P-FV-A complexes. Recently, another common viral integration site, Sic-1, rearranged in the non-T-, non-B-cell lymphomas induced by Cas-Br-E Moloney leukemia virus, has been shown to be identical to Fli-1 (Bergeron et al. 1990).

A cDNA clone corresponding to the Spi-1 transcript has been isolated from an FV-P-induced erythroleukemia cell line (Moreau-Gachelin et al. 1989). This transcript is highly expressed in both FV-P- and FV-A-induced erythroleukemia cell lines that have undergone rearrangements of the Spi-1 gene due to the insertion of SFFV (Moreau-Gachelin et al. 1989 1990). The sequence of the Spi-1 transcript has been shown recently to be identical to that of PU.1 (Goebl et al. 1990), a gene that encodes a DNA-binding protein (Klemsz et al. 1990). The PU.1 protein is also a transcriptional activator with $40 \%$ sequence identity to the proteins encoded by members of the ets oncogene family.

In the experiments reported here, we have identified a transcript that originates from sequences adjacent to the proviral integration sites defined by Fli-1. We show that this transcript is specifically up-regulated in leukemic clones with F-MuLV insertions at the Fli-1 locus and that Fli-1 encodes a new member of the ets family of DNA-binding proteins. Furthermore, we show that Fli-1 and c-ets-1 are located within $240 \mathrm{~kb}$ of each other on mouse chromosome 9 . These studies raise intriguing questions concerning the role of the ets family in normal and leukemic hematopoiesis and the specificity of integration events in retrovirally induced malignancies.

\section{Results \\ Isolation of cDNA corresponding to the Fli-1 locus}

Previously, we have identified a common site for integration of F-MuLV (Fli-1) in $75 \%$ of independently isolated erythroleukemia cell lines derived from either $\mathrm{BALB} / \mathrm{c}$ or NIH/Swiss mice inoculated at birth with FMuLV (Ben-David et al. 1990a). To determine whether this common integration event results in the activation of a novel transcript, we set out to identify and isolate a cDNA corresponding to the Fli-1 locus by using genomic probes that map around this integration site. We first determined the sites of F-MuLV integration at Fli-1 in seven erythroleukemia cell lines induced by F-MuLV. As shown in Figure 1, the provirus is integrated in the same $5^{\prime}$ to $3^{\prime}$ orientation in a $2-\mathrm{kb}$ region of genomic DNA. A number of erythroid and nonerythroid tumors were then analyzed by Northern blotting using several probes located adjacent to the Fli-1 integration sites. The probe B4 (Fig.1), which maps close to the region of the proviral integration sites, detected a 4 -kb mRNA in erythroleukemia cell lines with a rearranged Fli-1 locus. A smaller RNA species was also observed in the TPl cell line when total cellular RNA was used [this smaller transcript is not seen in poly $(\mathrm{A})^{+}$select RNA (data not shown)]. No Fli-1 transcript was observed in erythroleukemia cell lines induced with FV-P or FV-A with the B4 probe /data not shown).

To determine whether expression of this 4-kb mRNA was activated due to retroviral insertion and to determine the structure and protein-coding sequences of Fli-1, we constructed a $\lambda \mathrm{gt} 11 \mathrm{cDNA}$ library with the poly $(\mathrm{A})^{+}$ RNA isolated from an erythroleukemia cell line (CB7) that has a Fli-1 rearrangement. A total of $5 \times 10^{5}$ clones were screened with the B4 probe, and four clones were isolated. These clones all had a similar $1.7-\mathrm{kb}$ cDNA insert as determined by restriction enzyme mapping. Therefore, the insert from only one of these phage was purified and used in Northern blot analysis to determine its expression in erythroleukemia cell lines that either had a rearranged Fli-1 locus or still contained the intact allele. All three erythroleukemia cell lines, CB7, CB3, and TP1, induced by F-MuLV, expressed high levels of the $4.0-\mathrm{kb}$ transcript, whereas very low or undetectable levels of Fli-1 mRNA were observed in three other erythroleukemia cell lines (DP25-15, DP27-17, and DP28-9) induced by FV-P and only low levels of Fli-1 mRNA were observed in the erythroleukemia cell line DA24-23 induced by FV-A (Fig. 2). These latter four cell lines have a rearranged Spi-1 locus, but their Fli-1 locus was appar-

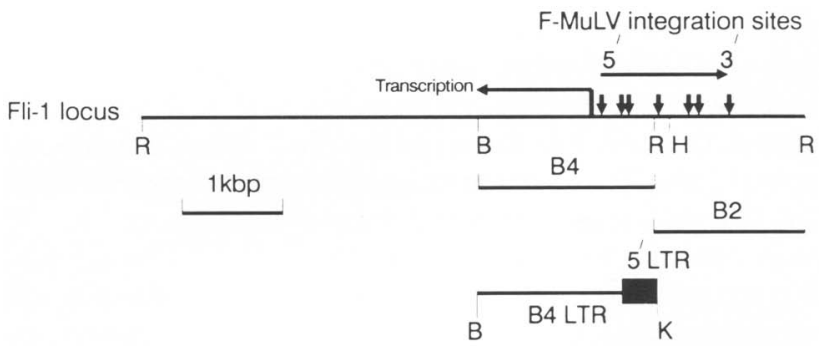

Figure 1. Identification of a transcription domain within the Fli-1 locus. The arrows indicate the sites and orientation of F-MuLV integration within the Fli-1 locus in seven erythroleukemia cell lines induced by F-MuLV. The 1.7-kb BamHI-EcoRI fragment (B4 probe) detects a $4-\mathrm{kb}$ transcript in erythroleukemias with a Fli-1 rearrangement. This 4 -kb transcript initiates within the B4 fragment (as indicated by arrow). The B4 LTR is a genomic fragment of Fli-1 that includes a portion of the integrated F-MuLV LTR isolated from the phage clone $\lambda \mathrm{C} 3$, as described previously (Ben-David et al. 1990a). The B4 LTR fragment contains sequences that correspond to the $5^{\prime}$ end of BB4 cDNA (see Fig. 3A). 


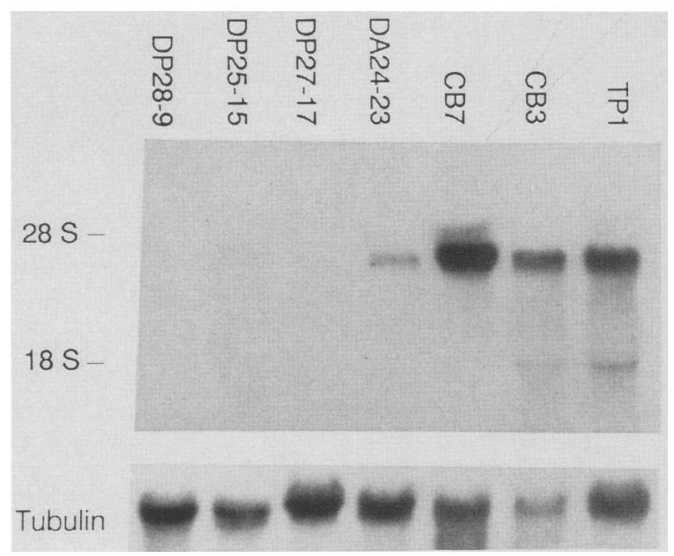

Figure 2. Expression of Fli-1 in both FV-P/FV-A- and F-MuLVinduced erythroleukemias. Twenty micrograms of total RNA extracted from the FV-P-induced erythroleukemia cell lines (DP28-9, DP25-15, and DP27-17), the FV-A-induced erythroleukemia cell line DA24-23, and the F-MuLV-induced erythroleukemia cell lines (CB7, CB3, and TP1) were electrophoresed and transferred to nitrocellulose paper and hybridized with the Fli-1 cDNA probe BB4 (see Fig. 3A). The same filter was rehybridized to the tubulin probe as a control and exposed for the same period of time ( $24 \mathrm{hr}$ ).

ently intact. The same filter was hybridized with a tubulin probe to control for RNA loading. The intensity of the bands detected with the Fli-1 probe was similar to that detected with the highly expressed tubulin probe. These data strongly suggest that the Fli-1 transcript detected with the B4 probe is highly expressed in F-MuLVinduced erythroleukemias and, therefore, might be a novel oncogene involved in the malignant progression of Friend leukemia.

\section{Sequence analysis of the Fli-1 transcript}

The insert from the $\lambda g t 11$ clone isolated with the B4 probe was subcloned into the PGEM-7Zf|+| vector (named BB4), and its complete nucleotide sequence was determined. As shown in Figure 3B, the sequence of the entire 1729-nucleotide insert contains a single long open reading frame of 1467 nucleotides. The 3 '-untranslated region extends for an additional 129 bases and has no poly(A) tail. There are three in-frame stop codons within the untranslated $3^{\prime}$ end. A putative translational initiation site is located $234 \mathrm{bp}$ from the $5^{\prime}$ end. The 5 '-untranslated region contains two stop signals upstream of the first methionine that has no consensus sequence typically found in eukaryotic translation initiation sites (Kozak 1986). The distinct boundaries around the open reading frame of BB4 cDNA suggested that this clone is capable of encoding a primary translation product initiating at the $5^{\prime}$-most AUG codon of 452 amino acids in length with an expected molecular mass of $51 \mathrm{kD}$.

\section{Fli-1 is a member of the ets gene family}

A search of the GenBank and EMBL DNA sequence data bases with the BB4 sequence revealed that Fli-1 is a new member of the ets gene family. The greatest similarity (67\% identity) of the BB4 sequence was to human erg2 (ets-related gene; Fig. 4) isolated on the basis of its crosshybridization with a c-ets-1 probe (Rao et al. 1987). The strong similarity between Fli-1 and Erg2 was found over the entire coding sequence, except between amino acids 200-265 of Fli-1. The similarity with erg2 extends from the fourth amino acid downstream of the putative initiation site of the Fli-l protein and both genes terminate with two conserved tyrosine residues at position 452 of Fli-1. The high degree of similarity immediately after the translational initiation site of erg2 suggests that Fli-1 translation also initiates at the same position. The overall protein identity between Fli-1 and Ets-1 is 30\% (Table 1). However, greater similarity $(68-100 \%)$ was found in an $\sim 85$ amino acid region located at the carboxy-terminal end of the three ets-related genes (Table 1). This region, termed the ETS domain (Karim et al. 1990), appears to be highly conserved among all of the Ets family members described to date. The Spi-1/PU.1 gene, which is activated in FV-P/FV-A-induced erythroleukemias, has only $23 \%$ overall identity to the Fli-1 protein sequence (Table 1), but $38 \%$ identity was found within the ETS domain of the Fli-1 and Spi-1/PU.1 proteins. The greatest similarity between Spi-1/PU.1 with other Ets family members within the ETS domain is $38 \%$ (with Ets-1). In addition to the 85-amino-acid ETS domain, we have identified a conserved 18- to 20-amino-acid region of Fli1 (amino acids 117-207) that contains high levels of similarity with Erg2 and Ets-1 (Fig. 4). Similar related regions have been shown previously between the protein sequences of Ergl and v-Ets (Reddy et al. 1987).

The Fli-1 protein shares with other members of the Ets family a hydrophilic sequence in the carboxy-terminal ETS domain. Fli-1 does not have zinc-finger consensus sequences or the consensus sequences for $\alpha$-helical turns found in other DNA-binding proteins with a helix-loophelix structure (Murre et al. 1989; Struhl 1989). However, there are three highly conserved tryptophan residues in the ETS domain of Fli-1, Erg2, and Ets-1 (Fig. 4, marked by asterisk). Similar patterns of tryptophan repeats are found in the v-myb DNA-binding region (Anton and Frampton 1988). Only the second and third tryptophan residues are conserved in the Spi-1/PU.1 ETS domain. The tryptophan residues conserved in the ets gene family and myb are not present in other DNA-binding proteins and, hence, they may serve to define a new category of DNA-binding proteins. In addition, there are three other conserved tryptophan residues in the more amino-terminal conserved region of Fli-1, Erg2, and Ets-1 (Fig. 4, shown by asterisk). The function and possible importance of these tryptophans are unknown at present.

\section{Transcriptional orientation of the Friend provirus relative to Fli-1}

Activation of a cellular oncogene by retroviral integration can occur by at least two known mechanisms, namely promoter insertion and enhancer activation. Pro- 
A

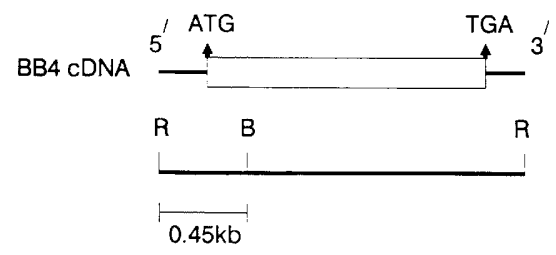

B

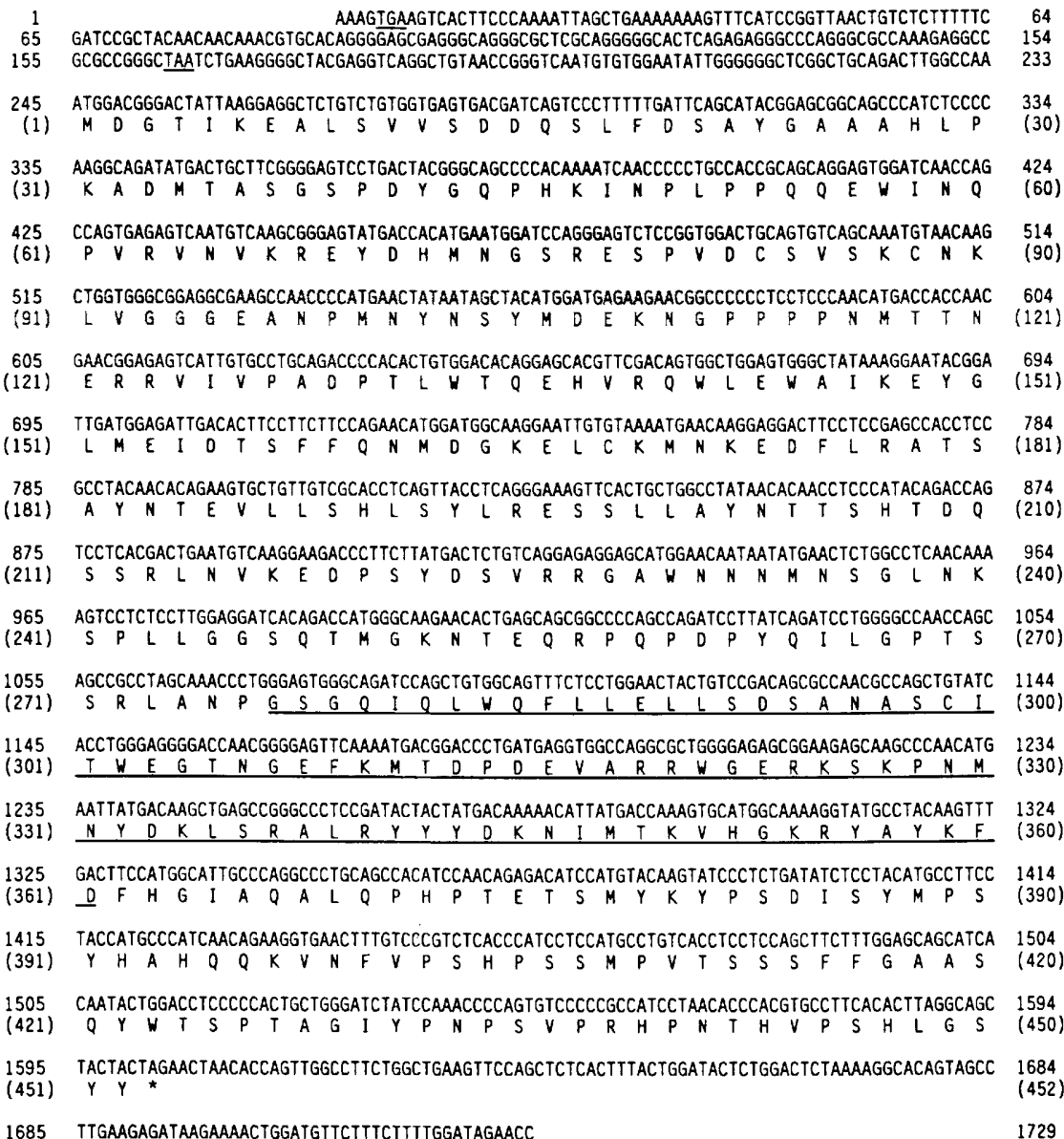

moter insertion requires that the transcriptional orientation of the proto-oncogene and the provirus be parallel and that the provirus be located $5^{\prime}$ of the start site of transcription, whereas enhancer activation can occur even if the provirus is in the transcriptionally opposite orientation and $3^{\prime}$ of the proto-oncogene. To define the mode of gene activation of Fli-1, we determined the orientation of provirus integration relative to $F l i-1$ in seven F-MuLV-induced erythroleukemia cell lines. As shown in Figure 1, the F-MuLV provirus integrated in the same $5^{\prime}$ to $3^{\prime}$ transcriptional orientation within $2 \mathrm{~kb}$ of Fli-1 (Ben-David et al. 1990a). B4 LTR is a BamHI-KpnI fragment that includes a portion of the integrated F-MuLV LTR and its $5^{\prime}$ Fli-1-flanking sequence derived from a genomic library constructed using DNA from the CB3 erythroleukemia cell line (Fig. 1). This 1.7-kb fragment hybridized with the 0.45-kb EcoRI-BamHI fragment from the $5^{\prime}$ end of the BB4 cDNA (Fig. 3A). This result demonstrates that the 5 ' sequence of BB4 cDNA is in the opposite transcriptional orientation relative to the orientation of the integrated provirus. Therefore, the Fli-1 transcript appears to be activated through the enhancer element of the LTR and not by direct promoter activity of the LTR. We also isolated $17 \mathrm{~kb}$ of sequences 3 ' to the integration site and were not able to detect sequences that hybridized with BB4 cDNA or mRNA corresponding to the Fli-1 transcript. Because the size of the activated transcript detected in Northern blot of F-MuLVinduced erythroleukemia cell lines is not altered, we suggest that the provirus integration sites are all located upstream of the Fli-1 transcriptional initiation site.

Fli-1 lies within $240 \mathrm{~kb}$ of the c-ets-1 proto-oncogene on mouse chromosome 9

Previously, we have mapped the Fli-1 locus using recombinant inbred (RI) strains of mice and shown that it is located within 0-2 cM of the c-ets-1 gene on mouse chro- 
Ben-David et al.
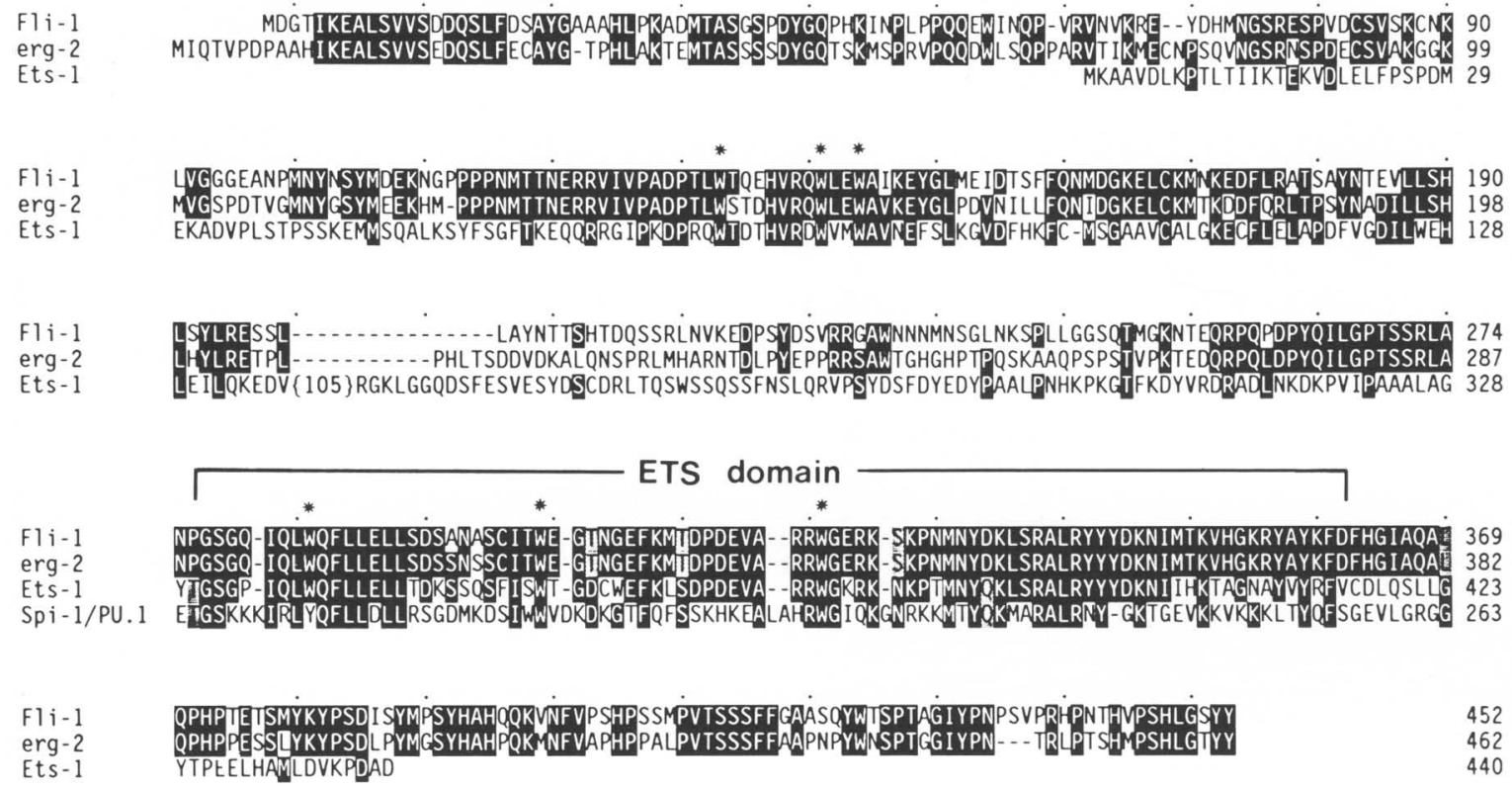

Figure 4. Comparative analysis of the Fli-1-coding sequence with the protein products of the Erg2, Ets-1, and Spi-1 genes. Amino acids shared by all four Ets proteins are marked in solid black. The amino acids shared by at least two of the four Ets proteins are either marked in solid black or are shaded. Gaps are indicated by hyphens. The $\{105\}$ symbol on the Ets-1-coding sequence indicates an additional 105 amino acids with no similarity to Fli-1 and Erg2. The $\sim 85$-amino-acid ETS domain in the carboxyl terminus of Fli-1, Erg2, Ets-1, and Spi-1 is marked (Karim et al. 1990). Conserved tryptophan residues are indicated by asterisks $\left({ }^{*}\right)$.

mosome 9 (Ben-David et al. 1990a). To define the physical linkage between Fli-1 and ets-1, we analyzed genomic fragments using pulsed field gel electrophoresis (PFGE). DNA from the erythroleukemia cell line DP2717 that does not have a rearrangement of either the Fli-1 or ets-1 genes was digested with SalI, Sfil, ClaI, NotI, and SacII and analyzed by Southern blotting using the c-ets-1 and B2 probes. The sizes of the DNA fragments that hybridized with the ets-1 and B2 probes were compared to identify fragments common to both probes. As shown in Figure 5 and indicated by arrows, DNA fragments of identical sizes hybridized with both the B2 and ets-1 probes when DNA was digested with SalI, SfiI, or NotI (indicated by arrows in lanes 1,2 , and 4 , respectively).

Table 1. Comparative analysis between the protein sequences of Fli-1, Erg2, Ets-1, and Spi-1/PU.1

\begin{tabular}{lccccc}
\hline & \multicolumn{2}{c}{ Entire protein $(\%)$} & & \multicolumn{2}{c}{ ETS domain $(\%)$} \\
\cline { 2 - 3 } \cline { 5 - 6 } & identity & similarity & & identity & similarity \\
\hline Fli-1 & 100 & 100 & & 100 & 100 \\
Erg-2 & 67 & 76 & & 98 & 98 \\
Ets-1 & 30 & 41 & & 68 & 80 \\
Spi-1/PU.1 & 23 & 33 & & 38 & 51 \\
\hline
\end{tabular}

Percent identity scores were calculated by dividing the number of identical amino acids by the total number of aligned amino acids. Percent similarity scores were calculated in the same way except that similar amino acids were considered similar: $\mathrm{G}=\mathrm{A}=\mathrm{L}=\mathrm{I}=\mathrm{V}=\mathrm{M} ; \quad \mathrm{S}=\mathrm{T} ; \quad \mathrm{D}=\mathrm{E} ; \quad \mathrm{H}=\mathrm{K}=\mathrm{R}$, $\mathrm{Y}=\mathrm{F}=\mathrm{W}$.
However, digestion with SacII gave rise to a large fragment $(>1000 \mathrm{~kb})$ with the ets-1 probe, whereas only a $200-\mathrm{kb}$ SacII fragment was detected with the B2 probe (Fig. 5, lane 5; and bands are marked by asterisks). Similarly, digestion with ClaI gave rise to two hybridizing bands with both the $\mathrm{B} 2$ and ets-1 probes, but these bands were of different sizes (Fig. 5, lane 3). Thus, the PFGE analysis suggests that $F l i-1$ and ets-1 are located on DNA fragments of the same size after digestion with Sall, SfiI, or NotI. The NotI digest was uninformative, as this fragment was $>1000 \mathrm{~kb}$ and migrated in the compression zone. However, both Fli-1 and ets-1 are located on common 350-kb Sall and 240-kb SfiI bands, which are well separated by PFGE. Therefore, the common 240-kb SfiI fragment defines the upper limit for the distance between the Fli-1 and c-ets-1 genes.

\section{Fli-1 expression in adult mouse tissues}

As examined by Northern blot (Fig. 6), the Fli-1 4-kb mRNA is highly expressed in adult tissues, including thymus, heart, muscle, and spleen. Low levels of Fli-1 expression were also detected in total RNA prepared from brain, kidney, and testes. In addition, small amounts of Fli-1 RNA were observed in liver (data not shown). Although there were some differences in the amount of RNA loaded on the lanes in the blot shown in Figure 6, this Northern blot analysis clearly shows that Fli-1 is expressed in both hematopoietic and nonhematopoietic tissues. The c-ets-1 proto-oncogene has been shown previously to be expressed in adult mice 


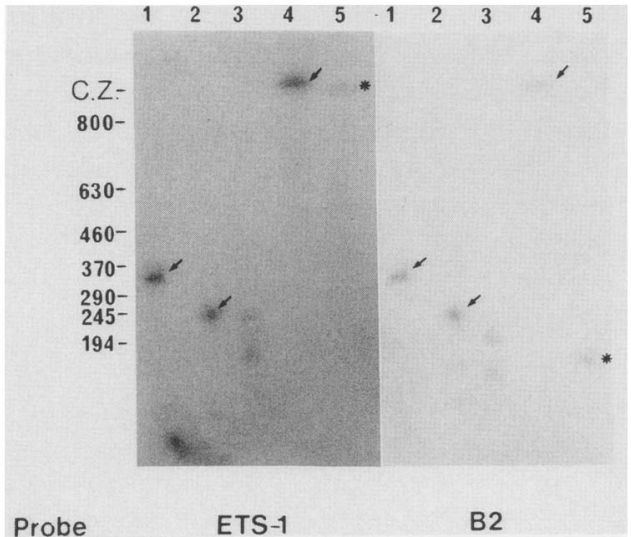

Figure 5. PFGE of the Fli-1 and ets-1 genes. High-molecularweight DNA from the erythroleukemia cell lines DP27-17 was embedded in agarose and digested with the restriction enzymes SalI (lane 1), SfiI (lane 2), ClaI (lane 3), NotI (lane 4), and SacII (lane 5), run on a PFGE apparatus. DNA was transferred to nitrocellulose paper. The filter was first hybridized with an ets-1 genomic probe and exposed to X-ray film. The probe was then stripped off and the same filter was rehybridized with an Fli-1 probe (probe B2, Fig. 1). The arrows indicate the identical bands. The asterisks $(*)$ show the two different bands generated with SacIl digestion after hybridizing the same filter with either the Fli-1 or ets-1 probes. (C.Z.) Compression zone.

only in hematopoietic tissues, particularly in thymus (Bhat et al. 1987). Thus, despite the close structural homology and physical linkage between Fli-1 and c-ets-1, these two genes appear to be under separate regulatory control.

\section{Dissussion}

Insertional activation of cellular genes by replicationcompetent retroviruses is a common pathway to malignant transformation and tumor progression, and thus provides a unique strategy to identify and clone new transforming genes. The results presented in this study demonstrate that the induction of erythroleukemia by F-MuLV frequently involves the activation of a novel

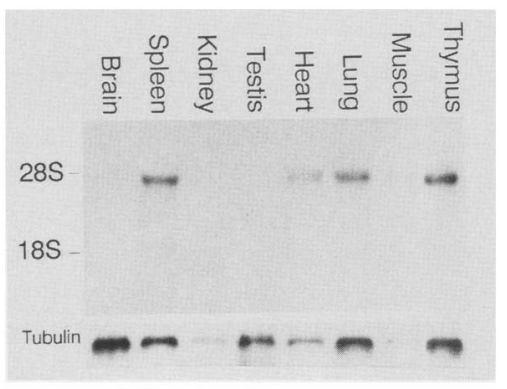

Figure 6. Expression of Fli-1 in mouse adult tissues. Total RNA (20 $\mu \mathrm{g}$ ) from adult tissues was electrophoresed, blotted to nitrocellulose, and hybridized with ${ }^{32} \mathrm{P}$-randomly primed BB4 cDNA. Tubulin is used to indicate the amount of RNA loaded on the gel. member of the ets family of transcription factors as a result of the integration of F-MuLV upstream of the Fli-1 locus. DNA and RNA analyses of Fli-1 and the adjacent F-MuLV provirus suggest that F-MuLV integration activates Fli-1 expression as the result of the strong enhancer activity of the Friend LTR in erythroid cells.

\section{Fli-1 is a member of the ets family}

A search of the translated GenBank and EMBL DNA sequence data bases for protein sequence similarity with the Fli-1 gene product revealed an overall high similarity with members of the ets gene family, particularly with the human erg2 gene. The ets gene family includes human ets-1 (Watson et al. 1988), murine ets-1 (Gunther et al. 1990), murine ets-2 (Watson et al. 1988), human erg (Reddy et al. 1987), human elk-1 and elk-2 (Rao et al. 1989), Drosophila E74 (Burtis et al. 1990), Drosophila ets-2 (Pribyl et al. 1988), and murine PU.1 (Klemsz et al. 1990). The Fli-1 protein is most similar to other members of the ets family in a region of $\sim 85$ amino acids close to the carboxyl terminus, designated the ETS domain (Karim et al. 1990). This domain appears to mediate the sequence-specific DNA binding of the Ets proteins to a purine-rich core DNA sequence. In addition, there is a region near the amino terminus that is conserved in the Ets-1 and Ets-2, Erg, v-Ets, and Fli-1 proteins.

The ets family of proto-oncogenes was first identified as the cellular homologes of $\mathrm{v}$-ets, one of the viral transforming genes of the avian retrovirus E26 (Leprince et al. 1983; Nunn et al. 1983). Both the v-ets-encoded protein and its cellular homologs (c-Ets-1 and c-Ets-2) localize to the nucleus and have DNA-binding activity (Boulukos et al. 1988; Fujiwara et al. 1988a; Pognonec et al. 1989|. The c-ets-1 and c-ets-2 genes are transiently activated and rapidly phosphorylated in response to mitogenic stimuli (Fujiwara et al. 1988b; Pognonec et al. 1988). These observations suggest that the ets gene family has regulatory roles, a view consistent with the oncogenic potential of $\mathrm{v}$-ets. The products of the c-ets-1 and c-ets-2 proto-oncogenes can also trans-activate promoter/enhancer sequences contained within the HTLV-1 and Moloney murine sarcoma virus LTRs (Bosselut et al. 1990; Gunther et al. 1990). Furthermore, Ets proteins interact or cooperate with c-Fos and c-Jun to activate transcription (Wasylyk et al. 1990). Taken together, these observations suggest that the mammalian ets family, including Fli-1, constitutes a novel and large group of transcriptional activators. Thus, the insertional activation of Fli-1 may directly enhance the transcription of other genes involved in malignant transformation of erythroid cells during the progression of Friend leukemia.

The ets-binding consensus sequence that is present in the Moloney sarcoma virus LTR is also found in the promoter regions of the SFFV LTR (Clark and Mak 1983) and the F-MuLV LTR (Holland et al. 1987). Both SFFV and F-MuLV integrate upstream of the Spi-1/PU.1 and Fli-1 genes in Friend erythroleukemia cell lines, respectively. Thus, activation of Fli-1 or PU.1 may create a 
positive feedback loop that enhances the expression of proviruses by binding to their LTR promoter sequences. Activation of the SFFV genome would also lead to increased synthesis of the SFFV-encoded gp55 glycoprotein, which has been shown to bind to the erythropoietin receptor and thereby eliminate dependency of erythroid cells for exogenous hormone ( $\mathrm{Li}$ et al. 1990). In addition, an increase in the production of SFFV or F-MuLV could enhance the probability of insertional activation or inactivation of other genes involved in erythroleukemia induction. One example could be the p53 tumor suppressor gene that is inactivated in a significant number of erythroleukemia cell lines as the result of Friend virus integration (Ben-David et al. 1990b).

\section{Amplification and dispersion of ets gene family members}

The deduced amino acid sequence of the Fli-1 protein is most similar to that of the human Erg2 protein and less so with Ets-1 and Spi-1/PU.1 (see Table 1). Overall, there is $67 \%$ identity between the mouse Fli-1 and the human Erg2 protein, whereas within the 84-amino-acid ETS domain there is $98 \%$ sequence identity between these two proteins. Similarly, the Ets-1 and Ets- 2 proteins share significant homology with each other and less so with Erg2 and Fli-1. The Spi-1/PU.1 protein appears to be an even more distant member of the Ets family.

Genetic and physical mapping has established that Fli1 and c-ets-1 are very closely linked in both the mouse and human genomes on chromosome 9 and 11, respectively. Similarly, c-ets-2 and erg2 are closely linked to each other on human chromosome 21 band q22.3 (Watson et al. 1985; Rao et al. 1987); and in the mouse, c-ets-2 maps to the syntenic region on mouse chromosome 16 (Cheng et al. 1988).

The chromosomal mapping and DNA sequence data discussed above suggest a model for the origin and dispersion of the various ets family members in which a primordial ets gene became duplicated and much later the pair of genes dispersed to other chromosomes. This model explains both the close sequence similarity between the unlinked Fli-1/erg2 and c-ets-1/c-/ets-2 genes, as well as the more limited degree of similarity between the closely linked ets genes (c-ets-1/Fli-1 and c-ets-2/ erg2).

In addition to the considerable sequence divergence between Fli-1 and c-ets-1, these genes display different patterns of expression in adult mouse tissues. These data suggest that despite their close physical linkage in mammalian genomes, Fli-1 and c-ets-1 are under distinct regulatory controls, reflecting perhaps sequence divergence extending into the transcriptional control regions.

Both Fli-1 and c-ets-1 are located in a region of the mouse genome that is syntenic with human chromosome $11 \mathrm{q} 23$. This region of the genome is a frequent site of breakpoints in a wide variety of human leukemias and lymphomas (Yunis and Brunning 1986). The 11q23 translocation can involve a number of other possible chromosomes, although the most common is chromosome 4q21
(Yunis et al. 1989). These rearrangements do not appear to be within the c-ets-1 gene itself. The close physical linkage between Fli-1 and c-ets-1, and the association of the ets family with experimental leukemias, raises the possibility that Fli-1 may be involved in leukemic transformation in patients with the $t(4 ; 11)$ translocation. Experiments are currently in progress to test this possibility.

\section{Multistage Friend erythroleukemia and sites for retrovirus integration}

The erythroleukemias induced by the various strains of Friend virus are the culmination of a multistep process that has served as a model for our understanding of the molecular events that underlie tumor initiation and progression (Ben-David and Bernstein 1989). At least two distinct stages of Friend leukemia have been recognized. The first stage is characterized by the polyclonal expansion of infected but preleukemic erythroid progenitor cells. This is followed by a second stage characterized by the clonal emergence of malignant, immortalized cells (Mager et al. 1981; Wendling et al. 1981). The polyclonal proliferation that characterizes the early stages of the disease induced by the defective Friend SFFV appears to result from the binding of the SFFV-encoded membrane glycoprotein gp 55 to the erythropoietin receptor ( $\mathrm{Li}$ et al. 1990).

Studies on the leukemic clones that emerge in the late stages of the disease induced by either the Friend virus complexes (FV-P or FV-A) or by F-MuLV alone have shown that inactivation of the p53 gene is a common, and perhaps obligate, event. These inactivation events include deletions (Mowat et al. 1985; Rovinski et al. 1987; Ben-David et al. 1988; Munroe et al. 1988), retroviral insertions (Ben-David et al. 1988; Hicks and Mowat 1988; Ben-David et al. 1990b), and point mutations (Munroe et al. 1990), frequently accompanied by a reduction to homozygosity. These observations provided evidence that p53 might be a tumor suppressor gene, a conclusion substantiated by the subsequent analysis of the p53 gene in in vitro immortalization/transformation assays (Rovinski and Benchimol 1988; Eliyahu et al. 1989; Hinds et al. 1990), and alteration of the p53 gene in human tumors (Lane and Benchimol 1990; Levine 1990).

In addition to $\mathrm{p} 53$ inactivation, the cellular Spi-1/PU.1 and Fli-1 genes are almost always activated as the result of viral integration events. Although Fli-1 and Spi-1 are distinct genes, they are both members of the ets family of DNA-binding proteins. We have shown previously that $F l i-1$ is only rearranged in erythroleukemias, not in myeloid or lymphoid tumors induced by F-MuLV (BenDavid et al. 1990a). Thus, Fli-1 and Spi-1 are both ets family members that, to date, only appear to be activated in erythroid neoplasms induced by different murine retroviruses. Given the biochemical similarities between Fli-1 and Spi-1/PU.1, their specificity for erythroleukemias, and their similar mechanism of activation by retroviral integration, it is surprising that there is strict 
specificity of oncogene activation; that is, Fli-1 is only activated in erythroleukemias induced by F-MuLV, whereas Spi-1 is only activated in leukemias induced by the Friend virus complexes. In 22 erythroleukemic clones, we have never observed Fli-1 activation by FV-P or FV-A or Spi-1 activation by F-MuLV (data not shown). There are two possible explanations for these observations. First, although Spi-1 and Fli-1 are both ets family members, they are clearly distinct, with limited identity in the highly conserved ETS domain (Table 1). Thus, Fli-1 and Spi-1 may trans-activate different genes because they recognize different DNA sequence elements and/or interact with distinct components of the transcriptional apparatus. However, the leukemic clones induced by infection with different strains of Friend virus are similar in their leukemic properties and in their erythroid characteristics, suggesting some overlap in the sets of genes trans-activated by Fli-1 and Spi-1.

A second explanation for the strict specificity of Fli-1 and Spi-1 activation may be related to differences in their target cells for erythroid transformation. The FV-P and FV-A complexes can induce erythroleukemias in either newborn or adult animals, whereas F-MuLV only induces erythroleukemias in newborn mice (Silver and Kozak 1986). The susceptibility of adult mice to FV-P or FV-A may be due to the expression of the gp55 glycoprotein resulting, as discussed above, in the polyclonal proliferation of cells that might otherwise not be susceptible to infection. Thus, it is possible that the Friend virus complexes and F-MuLV have distinct target cells for transformation. If the chromatin structure around Fli-1 and Spi-1 undergoes changes during hematopoiesis, it is possible that the susceptibility of these genes to retroviral integration events also may change during cellular differentiation. Analysis of integration sites used after infection of turkey embryo fibroblasts by an avian retrovirus has suggested that there are a limited number of sites $(\sim 1000)$ available for integration events (Shih et al. 1988). The basis for this selectivity is unknown, but if the strict specificty for Fli-1 and Spi-1 integration events is related to stage of erythroid differentiation, the spectrum of sites available for retrovirus integration may vary with developmental stage. Thus, the total number of such sites within a species may be larger than estimated from examining a single cell type.

It should be possible to test these models by generating transgenic animals that either carry additional copies of Fli-1 or Spi-1, or have sustained loss-of-function mutations in these genes by gene targeting. Such mutant mice should also be useful in determining whether ets genes are involved in the differentiation of normal hematopoietic stem cells, a possibility raised by the findings that three members of the ets family (v-ets, Fli-1, and Spi-1) are all involved in erythroleukemia induction in chickens and mice, respectively.

\section{Materials and methods}

Cells

The erythroleukemia cell lines DP25-15, DP27-27, DP28-9, and
DA24-33 were derived from methylcellulose colonies of spleen cells of DBA/2 adult mice that had been injected with either the polycythemia or anemia-inducing strains of Friend virus complex (FV-P or FV-A), as described previously (Ben-David et al. 1990b). The CB3 and CB7 cell lines were derived from the spleens of BALB/c mice injected at birth with F-MuLV helper virus (Shibuya and Mak 1983). The TP3 and TP1 cell lines were derived from the spleen of a NIH/Swiss mouse infected at birth with F-MuLV (Oliff et al. 1984). Cells were maintained in $\alpha$ minimal essential medium ( $\alpha$ MEM) supplemented with $10 \%$ fetal calf serum.

\section{Construction of cDNA library and isolation of cDNA clones}

A $\lambda \mathrm{gt} 11 \mathrm{cDNA}$ expression library was constructed from $5 \mu \mathrm{g}$ of poly $(\mathrm{A})^{+}$RNA isolated from the erythroleukemia cell line CB7, using a Pharmacia cDNA synthesis kit as described previously (Ben-David et al. 1991). The library $\left(10^{6}\right.$ phages) was amplified once and stored at $4^{\circ} \mathrm{C}$. To isolate cDNA clones, $5 \times 10^{5}$ phages were screened with the genomic probe B4; after three rounds of plaque purification, four colonies were recovered from the cDNA library.

\section{Subcloning and nucleotide sequence determination}

DNA was prepared from plaque-purified phage according to standard procedures using lambdasorb phage absorbent (Promega) and subcloned into pGEM-7Zf $(+$ ) or pGEM-7Zf $(-)$. The plasmid DNA was isolated using cesium chloride gradients, as described previously (Chirgwin et al. 1979). For complete sequence determination, nested deletions spanning the cDNA insert of the desired clone were generated using the method of Henikoff (Henikoff 1987). These constructs were rescued as ssDNA after superinfection of bacteria with the coliphage M13K07 and sequenced by the dideoxynucleotide chain termination method using Sequenase enzyme, reagents, and protocols supplied by U.S. Biochemical. Sequence was obtained from both strands.

\section{Nucleic acid probes}

The B4 probe was a $1.7-\mathrm{kb}$ BamHI-EcoRI genomic fragment located within the site of provirus integration (Fig. 1) isolated from a $\lambda$ phage genomic clone that contained the nonrearranged Fli-1 locus (Ben-David et al. 1990a). The B4 LTR was a 1.7-kb $B a m H I-K p n I$ fragment that was isolated from a $\lambda c 3$ phage clone (Ben-David et al. 1990a) and contained the sequences corresponding to the $5^{\prime}$ F-MuLV LTR and sequences immediately adjacent to the provirus integration site (Fig. 1). The BB4 cDNA was a $1.7-\mathrm{kb}$ EcoRI fragment subcloned from a $\lambda \mathrm{gt} 11$ phage clone that was isolated using the B4 probe (Fig. 3A). The B2 probe was the 1.5-kb EcoRI genomic fragment of the Fli-1 locus (Fig. 1) and the ets-1 probe was a genomic fragment of the mouse c-ets-1 oncogene (kindly provided by R.H. Reeves, Frederick Cancer Research Center, Frederick, MD). The DNA probes were freed from plasmid sequences, gel-purified, and labeled by random priming (Feinberg and Vogelstein 1983).

\section{RNA extraction and Northern blotting}

Total cellular RNA from erythroleukemia cell lines was isolated essentially as described previously (Auffray and Rougeon 1980). In brief, $10^{8}$ cells were lysed in $200 \mu \mathrm{l}$ of $0.1 \mathrm{M} \mathrm{NaCl}, 0.1$ $\mathrm{M}$ Tris $(\mathrm{pH} 7.9)$, and $0.65 \%$ NP-40. Cell extracts were centrifuged for $2 \mathrm{~min}$ in a microcentrifuge (Eppendorf). An equal volume of buffer containing $7 \mathrm{M}$ urea, $0.35 \mathrm{M} \mathrm{NaCl}, 0.01 \mathrm{M}$ Tris $[\mathrm{pH}$ 
7.4), $0.01 \mathrm{M}$ EDTA, and $1 \%$ SDS was added to the lysate supernatant, and three extractions were performed with water-saturated phenol and chloroform $(1: 1)$ and one extraction was performed with chloroform. The final aqueous phase was precipitated with ethanol and stored in $100 \%$ ethanol at $-70^{\circ} \mathrm{C}$. Polyadenylated RNAs were selected by affinity chromatography on oligo(dT)-cellulose (Pharmacia) as described by the supplier.

Total RNA from mouse tissues was isolated according to the lithium chloride precipitation method described previously (Auffray and Rougeon 1980). In brief, tissues were removed from a number of adult BALB/c mice, homogenized in $10 \mathrm{ml}$ of lithium chloride solution ( $3 \mathrm{LiCl}, 6 \mathrm{M}$ urea), and incubated for $20-24$ hr at $4^{\circ} \mathrm{C}$. The RNAs were precipitated by centrifugation for 20 min at $17,000 \mathrm{~g}$. The pellets were resuspended in $6 \mathrm{ml}$ of lithium chloride/urea solution and centrifuged for $20 \mathrm{~min}$ at $17,000 \mathrm{~g}$. The RNA pellets were dried and sequentially extracted at room temperature twice with $2 \mathrm{ml}$ of phenol/chloroform $(1: 1)$ and once with $2 \mathrm{ml}$ of chloroform. The RNA was precipitated with ethanol and resuspended in TE.

Total RNA $(20 \mu \mathrm{g})$ was dissolved in $2.2 \mathrm{M}$ formaldehyde and $50 \%$ formamide denatured at $65^{\circ} \mathrm{C}$ for $5 \mathrm{~min}$, and electrophoresed in a $1 \%$ agarose gel containing $0.66 \mathrm{M}$ formaldehyde. After transfer to nitrocellulose, the filter was hybridized with $2 \times 10^{6}$ $\mathrm{cpm}$ of random primed probe per milliliter of hybridization mixture that contained $50 \%$ formamide, $10 \%$ dextran sulfate, $1.5 \times$ SSC $(1 \times$ SSC $=0.15 \mathrm{M}$ sodium citrate at $\mathrm{pH} 7), 5 \times$ Denhardt's solution $(1 \times$ Denhardt's solution $=0.02 \%$ bovine serum albu$\min / 0.02 \%$ Ficoll $/ 0.02 \%$ polyvinylpyrrolidonel, and denatured salmon sperm DNA $(100 \mathrm{mg} / \mathrm{ml})$ at $42^{\circ} \mathrm{C}$ (Southern 1975; Sambrook et al. 1989). The filter was washed with $0.1 \times$ SSC and $0.1 \%$ SDS at $65^{\circ} \mathrm{C}$.

\section{PFGE}

High-molecular-weight DNA for PFGE analysis was prepared from the erythroleukemia cell line DP27-17 as described previously (Sambrook et al. 1989). The DNA from $\sim 2 \times 10^{5}$ cells was embedded in agarose blocks and digested with the rare restriction enzyme cutters SalI, SfiI, NotI, ClaI, and SaclI by incubating for $16-20 \mathrm{hr}$ at $37^{\circ} \mathrm{C}$ except for plugs digested with SfiI, which were incubated at $50^{\circ} \mathrm{C}$. The digested DNA samples were run on gels ( $1 \%$ agarose in $45 \mathrm{M}$ Tris-borate/l M EDTA) for $24 \mathrm{hr}$ with a switch time of $30 \mathrm{sec}$ initial, $80 \mathrm{sec}$ final, ramped over 24 $\mathrm{hr}$ and a field strength of $90 \mathrm{~mA} / 170 \mathrm{~V}$ (Southern et al. 1987). Intact Saccharomyces cerevisiae YNN295 yeast chromosomal DNA and $\lambda$ phage DNA were used as molecular weight markers. DNA was transferred to Gene Screen Plus membrane (Biotechnology Systems, Dupont), UV cross-linked, and hybridized to ${ }^{32} \mathrm{P}$-labeled random primed probes as described above for RNA blotting.

\section{Computer analysis}

Sequences were compared with the GenBank (Bilofsky et al. 1986) and EMBL (Hamm and Cameron 1986) data bases using the Genetics Computer Group (GCC) programs (Devereux et al. 1984), and the automatic FASTA service provided by GenBank via electronic mail. The GCC programs were used for initial alignment while final alignment were done using the Maligned program (S. Clark, unpubl.).

\section{Acknowledgments}

We thank Andrew Poulos for assistance with the DNA cloning and sequencing, Mike Barrett and Derrick Rossi for their con- tributions to the PFGE analysis, Steve Clark for help in the computer analysis, Alex Joyner, Alain Lavigueur, and Lesley Forrester for their comments on the manuscript, and Sherry Mackey and Donnet Queensborough for help in preparation of the manuscript. This work was supported by a grant from the National Cancer Institute of Canada and by the Leukemia Research Fund of Canada.

The publication costs of this article were defrayed in part by payment of page charges. This article must therefore be hereby marked "advertisement" in accordance with 18 USC section 1734 solely to indicate this fact.

\section{Note added in proof}

Sequence data described in this paper have been submitted to EMBL/GenBank Data Libraries under accession number X59421 mouse, FLI-1 CDNA.

\section{References}

Anton, I.A. and J. Frampton. 1988. Tryptophans in myb proteins. Nature 336: 719 .

Auffray, C. and F. Rougeon. 1980. Purification of mouse immunoglobulin heavy-chain messenger RNAs from total myeloma tumor RNA. Eur. I. Biochem. 107: 303-314.

Ben-David, Y. and A. Bernstein. 1989. Friend virus-induced erythroleukemia: A multistage malignancy. Ann. N.Y. Acad. Sci. 567: 165-170.

Ben-David, Y., V.R. Prideaux, V. Chow, S. Benchimol, and A. Bernstein, A. 1988. Inactivation of the p53 oncogene by internal deletion or retroviral integration in erythroleukemic cell lines induced by Friend leukemia virus. Oncogene 3: 179-185.

Ben-David, Y., E.B. Giddens, and A. Bernstein. 1990a. Identification and mapping of a common proviral integration site Fli-1 in erythroleukemia cells induced by Friend murine leukemia virus. Proc. Natl. Acad. Sci. 87: 1332-1336.

Ben-David, Y., A. Lavigueur, G.Y. Cheong, and A. Bernstein. $1990 \mathrm{~b}$. Insertional inactivation of the $\mathrm{p} 53$ gene during Friend leukemia: A new strategy for identifying tumor suppressor genes. The New Biologist 2: 1015-1023.

Ben-David, Y., K. Letwin, L. Tannock, A. Bernstein, and T. Pawson. 1991. A mammalian protein kinase with potential for serine/threonine and tyrosine phosphorylation is related to cell cycle regulation. EMBO I. 10: 317-325.

Bergeron, D., L. Poliquin, C.A. Kozak, and E. Rassart. 1990. Identification of a common viral integration region in Cas$\mathrm{Br}-\mathrm{E}$ murine leukemia virus-induced non-T, non-B cell lymphomas. J. Virol. 65: 7-17.

Bhat, N.K., R.J. Fisher, S. Fujiwara, R. Ascione, and T.S. Papas. 1987. Temporal and tissue-specific expression of mouse ets genes. Proc. Natl. Acad. Sci. 84: 3161-3165.

Bilofsky, H.S., C. Burks, J.W. Fickette, W.B. Goad, F.I. Lewitter, W.P. Rindone, C.D. Swindell, and C.S. Tung. 1986. The GenBank genetic sequence data bank. Nucleic Acids Res. 14: 14.

Bosselut, R., J.F. Duvall, A. Gegonne, M. Bailly, A. Hemar, J. Brady, and J. Ghysdal. 1990. The product of the ets-1 protooncogene and the related Ets 2 protein act as transcriptional activators of the long-terminal repeat of human $T$ cell leukemia virus HTLV-1. EMBO J. 9: 3137-3144.

Boulukos, K.E., P. Pognonec, A. Begue, F. Galibert, J.C. Gesquiere, D. Stehelin, and J. Ghysdael. 1988. Identification in chickens of an evolutionarily conserved cellular ets-2 gene (c-ets-2) encoding nuclear proteins related to the products of the c-ets proto-oncogene. $E M B O$ J. 7: 697-705. 
Burtis, K.C., C.S. Thummel, C.W. Jones, F.D. Karim, and D.S. Hogness. 1990. The Drosophila 74EF early puff contains E74, a complex ecdysone-inducible gene that encodes two etsrelated proteins. Cell 61: 85-99.

Cheng, S.V., J.H. Nadeau, R.E. Tanzi, P.C. Watkins, J. Jagadesh, B. Taylor, J.L. Haines, N. Sacchi, and J.F. Gusella. 1988. Comparative mapping of DNA markers from the familial Alzheimer disease and Down syndrome regions of human chromosome 21 to mouse chromosome 16 and 17. Proc. Natl. Acad. Sci. 85: 6032-6036.

Chirgwin, J.M., A.E. Przylbyla, R.J. MacDonald, and W. J. Rutter. 1979. Isolation of biologically active ribonucleic acid from sources enriched in ribonuclease. Biochemistry 18: 5294-5299.

Clark, S.P. and T.W. Mak. 1983. Complete nucleotide sequence of an infectious clone of Friend spleen focus-forming provinus: gp55 in an envelope fusion glyclprotein. Proc. Natl. Acad. Sci. 80: 5037-5041.

Devereux, J., P. Haeberli, and O. Smithies. 1984. A comprehensive set of sequence analysis programs for the VAX. Nucleic Acids Res. 12: 387-395.

Eliyahu, D., D. Michalo, S. Eliyahu, O. Pinhasi-Kimhi, and M. Oren. 1989. Wild type p53 can inhibit oncogene-mediated focus formation. Proc. Natl. Acad. Sci. 86: 8763-8767.

Feinberg, A.P. and B. Vogelstein. 1983. A technique for radiolabelling DNA restriction endonucleases fragments to high specific activity. Anal. Biochem. 132: 6-13.

Fujiwara, S., R.S. Fisher, A. Seth, N.K. Bhat, S.D. Showalter, M. Zewing, and T.S. Papas. 1988a. Characterization and localization of the products of the human homologue of the v-ets oncogene. Oncogene 2: 99-103.

Fujiwara, S., R.S. Fisher, N.K. Bhat, S. Espina, and T.S. Papas. 1988b. A short-lived nuclear phosphoprotein encoded by the human ets-2 proto-oncogene is stabilized by activation of protein kinase C. Mol. Cell. Biol. 8: 4700-4706.

Goebl, M.G., F. Moreau-Gachelin, D. Ray, P. Tambourin, A. Tavitian, M.J. Klemsz, S.C. McKercher, C. van Beveren, and R.A. Maki. 1990. The PU.I transcription factor is the product of the putative oncogene Spi-1. Cell 61: 1165-1166.

Gunther, C.V., J.A. Nye, R.S. Bryner, and B.J. Graves. 1990 Sequence-specific DNA binding of the proto-oncoprotein ets-1 defines a transcriptional activator sequence within the long-terminal repeat of the Moloney murine sarcoma virus. Genes \& Dev. 4: 667-679.

Hamm, G.H. and G.N. Cameron. 1986. The EMBL data library. Nucleic Acids Res. 14: 5-10.

Henikoff, S. 1987. Unidirectional digestion with exonuclease III in DNA sequence analysis. Methods Enzymol. 155: 156165.

Hicks, G.G. and M. Mowat. 1988. Integration of Friend murine leukemia virus into both alleles of the p53 oncogene in an erythroleukemia cell line. /. Virol. 62: 4752-4755.

Hinds, P.W., C.A. Finlay, R.S. Quartin, S.J. Baker, E.R. Fearon, B. Vogelstein, and A.J. Levine. 1990. Mutant p53 DNA clones from human colon carcinomas co-operate with ras in transforming primary Rat cells: A comparison of the "Hot Spot" mutant phenotypes. Cell Growth Differ. 1: 571-580.

Holland, C.A, P. Anklesaria, A. Sakakeeny, and J.S. Greenberger. 1987. Enhancer sequences of a retroviral vector determine expression of a gene in multipotent hematopoietic progenitors and committed erythroid cells. Proc. Nat1. Acad. Sci. 84: 8662-8666.

Kabat, D. 1990. Molecular biology of Friend viral erythroleukemia. Curr. Top. Microbiol. Immunol. 148: 1-42.

Karim, F.D., L.D. Urness, C.S. Thummel, M.J. Klemsz, S.R. McKercher, A. Celada, C. Van Beveren, R.A. Maki, C.V.
Gunther, J.A. Nye, and B.J. Graves. 1990. The ETS-domain: A new DNA-binding motif that recognizes a purine-rich core DNA sequence. Genes \& Dev. 4: 1451-1453.

Klemsz, M.J., S.R. McKercher, A. Celada, C.V. Beveren, and R.A. Maki. 1990. The macrophage and B cell-specfic transcription factor PU. 1 is related to the ets oncogene. Cell 61: 113-124.

Kozak, M. 1986. Point mutations define a sequence flanking the AUG initiator codon that modulates translation by eukaryotic ribosomes. Cell 44: 283-292.

Lane, D. and S. Benchimol. 1990. p53: Oncogene or anti-oncogene? Genes \& Dev. 4: 1-8.

Leprince, D., A. Gegonne, J. Coll, C. de Taisne, A. Schneeberger, C. Lagrou, and D. Stehelin. 1983. A putative second cellderived oncogene of the avian leukaemia retrovirus E26. $\mathrm{Na}$ ture 306: 395-397.

Levine, A.J. 1990. Tumor suppressor genes. Bioessays 12: 6066.

Li, J.P., A.D. D'Andrea, H.F. Lodish, and D. Baltimore. 1990. Activation of cell growth by binding of Friend spleen focusforming virus gp55 glycoprotein to the erythropoietin receptor. Nature 343: 762-764

Mager, D.L., T.W. Mak, and A. Bernstein. 1981. Quantitative colony method for tumorigenic cell transformed by two distinct strains of Friend leukemia virus. Proc. Natl. Acad. Sci. 78: 1703-1707.

Metcalf, D. 1988. The molecular control of blood cells. Harvard University Press, Cambridge, MA.

Moreau-Gachelin, F., A. Tavitian, and P. Tambourin. 1988. Spi1 is a putative oncogene in virally induced murine erythroleukemias. Nature 331: 277-280.

- 1989. The putative oncogene Spi-1: Murine chromosomal localization and transcriptional activation in murine acute erythroleukemias. Oncogene 4: 1449-1456.

Moreau-Gachelin F., D. Ray, N.J. de Both, M.J.M. van der Feltz, P. Tambourin, and A. Tavitian. 1990. Spi-1 oncogene activated in Rauscher and Friend murine virus-induced acute erythroleukemias. Leukemia 4: 20-23.

Mowat, M., A. Cheng, N. Kimura, A. Bernstein, and S. Benchimol. 1985. Rearrangements of the cellular p53 gene in erythroleukemic cells transformed by Friend virus. Nature 314: 633-636.

Munroe, D.G., B. Rovinski, A. Bernstein, and S. Benchimol. 1988. Loss of the highly conserved domain on p53 gene in erythroleukemia cells transformed by Friend virus. Oncogene 2: 621-624.

Munroe, D.G., J.W. Peacock, and S. Benchimol. 1990. Inactivation of the cellular p53 gene is a common feature of Friend erythroleukemia: Relation to dominant transforming alleles. Mol. Cell. Biol. 10: 3307-3313.

Murre, C., P.S. McCaw, and D. Baltimore. 1989. A new DNA binding and dimerization motif in immunoglobulin enhancer binding, daughterless, MyoD, and myc proteins. Cell 56: 777-783.

Nunn, M.F., P.H. Seeburg, C. Moscovici, and P.H. Duesberg. 1983. Tripartite structure of the avian erythroblastosis virus E26 transforming gene. Nature 306: 391-395.

Oliff, A., I. Oliff, B. Schmidt, and N. Famulari. 1984. Isolation of immortal cell lines from the first stage of murine leukemia virus-induced leukemia. Proc. Nat1. Acad. Sci. 81: 5464 5467.

Pawson, T. and A. Bernstein. 1990. Receptor tyrosine kinases: genetic evidence for their role in Drosophila and mouse development. Trends Genet. 6: 350-356.

Peters, G. 1990. Oncogenes at viral integration sites. Cell Growth Differ. 1: 503-510. 
Pognonec, P., K.E. Boulukos, J.C. Gesquiere, D. Stehelen, and J. Ghysdael. 1988. Mitogenic stimulation of thymocytes results in the calcium-dependent phosphorylation of c-ets-1 protein. EMBO J. 7: 977-983.

Pognonec, P., K.E. Boulukos, and J. Ghysdael. 1989. The c-ets-1 protein is chromatin associated and binds to DNA in vitro. Oncogene 4: 691-697.

Pribyl, L.J., D.K. Watson, M.J. McWilliams, R. Ascione, and T.S. Papas. 1988. The Drosophila ets-2 gene: Molecular structure, chromosomal localization and developmental expression. Dev. Biol. 127: 45-53.

Rao, V.N., T.S. Papas, T.S. and S.P. Reddy. 1987. erg, a human ets-related gene on chromosome 21: Alternative splicing, polyadenylation, and translation. Science 237: 635-639.

Rao, V.N., K. Huebner, M. Isobe, A. Ar-Rusheli, C.M. Croce, and E.S.P. Reddy. 1989. elk, tissue-specific ets-related genes on chromosomes $\mathrm{X}$ and 14 near translocation breakpoints. Science 244: 66-70.

Reddy, E.S.P., V.N. Rao, and T.K. Papas. 1987. The erg gene: A human gene related to the ets oncogene. Proc. Natl. Acad. Sci. 84: 6131-6135.

Rovinski, B., D. Munroe, J. Peacock, M. Mowat, A. Bernstein, and S. Benchimol. 1987. Deletion of $5^{\prime}$-coding sequences of the cellular p53 gene in mouse erythroleukemia: A novel mechanism of oncogene regulation. Mol. Cell. Biol. 7: 847853.

Rovinski, B. and S. Benchimol. 1988. Immortalization of rat embryo fibroblasts by the cellular p53 oncogene. Oncogene 2: $445-452$.

Sachs, L. 1987. The molecular control of blood cell development. Science 238: 1374-1379.

Sambrook, J., F. Fritsch, and T. Maniatis. 1989. Molecular cloning: A laboratory manual, 2nd ed. Cold Spring Harbor Press, Cold Spring Harbor, New York.

Shibuya, T. and T. Mak. 1983. Isolation and induction of erythroleukemic cell lines with properties of erythroid progenitor burst-forming cell (BFU-E) and erythroid precursor cell (CFU-E). Proc. Natl. Acad. Sci, 80: 3721-3725.

Shih, C.C., J.P. Stoye, and J.M. Coffin. 1988. Highly preferred targets for retrovirus integration. Cell 53: 531-537.

Silver, J. and C. Kozak. 1986. A common integration region on mouse chromosome 7 in lymphomas induced by Friend murine leukemia virus (F-MuLV). I. Virol. 57: 526-533.

Southern, E.M. 1975. Detection of specific sequences among DNA fragments separated by electrophoresis. I. Mol. Biol. 98: 503-517.

Southern, E.M., R. Anand, W.R.A. Brow, and D.S. Fletcher. 1987. A model for the separation of large DNA molecules by crossed field gel electrophoresis. Nucleic Acids Res. 15: 5925-5943.

Struhl, K. 1989. Helix-turn-helix, zinc finger and leucine-zipper motifs for eukaryotic transcriptional regulatory proteins. Trends Genet. 14: 137-140.

Wasylyk, D., C. Wasylyk, P. Flores, A. Begue, D. Leprince, and D. Stehelin. 1990. The c-ets proto-oncogenes encode transcription factors that cooperate with c-fos and c-jun for transcriptional activation. Nature 346: 191-193.

Watson, D.K., M.J. McWilliams-Smith, M.F. Nunn, P.H. Duesberg, S.J. O'Brien, and T.S. Papas. 1985. The ets sequence from the transforming gene of avian erythroblastosis virus, E26, has unique domains on human chromosomes 11 and 21 . Both loci are transcriptionally active. Proc. Natl. Acad. Sci. 82: 7294-7298.

Watson, D.K., M.J. McWilliams, P. Lapis, J.A. Lautenberger, C.W. Schweinfest, and T.S. Papas. 1988. Mammalian ets-1 and ets- 2 genes encode highly conserved proteins. Proc.
Natl. Acad. Sci. 85: 7862-7866.

Wendling, F., F. Moreau-Gachelin, and P. Tambourin. 1981. Emergence of tumorigenic cells during the course of Friend virus leukemia. Proc. Nat1. Acad. Sci. 78: 3614-3618.

Yunis, J.J. and R.D. Brunning. 1986. Prognostic significance of chromosomal abnormalities in acute leukemias and myelodrysplastic syndromes. Clin. Haematol. 15: 597-620.

Yunis, J.J., C. Jones, M.T. Madden, D. Lu, and M.G. Mayer. 1989. Gene order, amplification and rearrangement of chromosome band $11 \mathrm{q} 23$ in hematologic malignancies. Genomics 5: 84-90. 


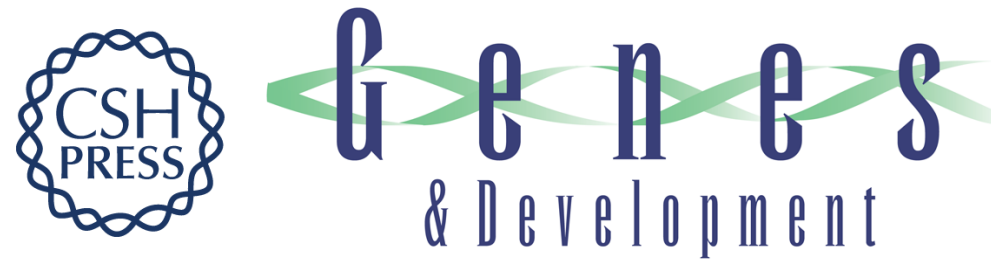

\section{Erythroleukemia induction by Friend murine leukemia virus: insertional activation of a new member of the ets gene family, Fli-1, closely linked to c-ets-1.}

Y Ben-David, E B Giddens, K Letwin, et al.

Genes Dev. 1991, 5:

Access the most recent version at doi:10.1101/gad.5.6.908

References This article cites 69 articles, 25 of which can be accessed free at: http://genesdev.cshlp.org/content/5/6/908.full.html\#ref-list-1

License

Email Alerting Service

Receive free email alerts when new articles cite this article - sign up in the box at the top right corner of the article or click here.

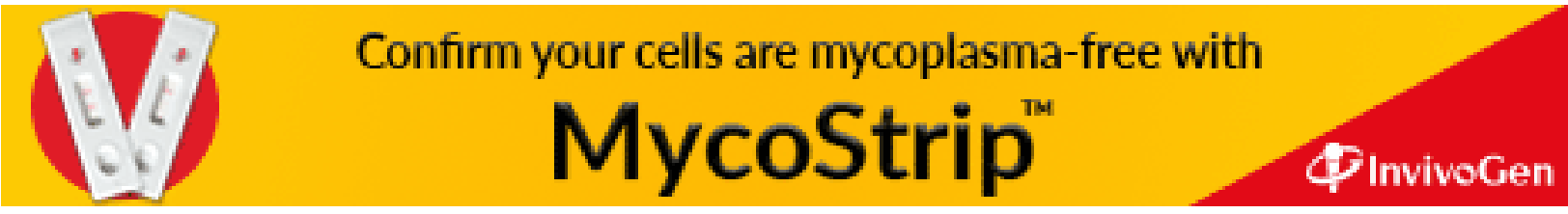

